\title{
An investigation on the nutrient and material effects of bark in komatsuna and tomato growing tests by using pots to determine the optimum mixed combination
}

\author{
Masafumi Tateda ${ }^{1^{*}}$, Mayuko Deguchi ${ }^{1}$, Yukihiro Kaji $^{2}$ \\ ${ }^{1}$ Department of Environmental Engineering, Toyama Prefectural University, Imizu, Japan; \\ *Corresponding Author: tateda@pu-toyama.ac.jp \\ ${ }^{2}$ Hokuriku Port Service Corporation, Imizu, Japan
}

Received 19 March 2013; revised 20 April 2013; accepted 15 May 2013

Copyright (C) 2013 Masafumi Tateda et al. This is an open access article distributed under the Creative Commons Attribution License, which permits unrestricted use, distribution, and reproduction in any medium, provided the original work is properly cited.

\begin{abstract}
The effects of bark on komatsuna (Japanese spinach) and tomato were investigated by changing the nitrogen content of chemical fertilizers and bark mixing ratio. Mixing 25 and $50 \%$ of bark with soil improved komatsuna growth, and also exceeded the growth rates obtained by using chemical fertilizers. However, komatsuna could not grow in $100 \%$ bark alone, with excessive amounts of bark majorly inhibiting komatsuna growth. The aeration of bark also did not enhance komatsuna growth. The nitrogen content and bark-mixing ratio had a much lower impact on tomato growth compared to komatsuna. In comparison, aerated bark was more effective in enhancing tomato growth compared to komatsuna growth.
\end{abstract}

Keywords: Bark; Fertilizer; Pot Test; Growing Test; Komatsuna; Tomato

\section{INTRODUCTION}

Some small Japanese communities use bark as a soil conditioner or compost, with demand always exceeding supply; however, such cases are generally rare, with bark often being disposed as waste [1-4]. Various uses of bark have been researched in an effort to promote its use. Due to the adsorption capability of bark, boron fixation [5], ammonia emission reduction [3], and the production of activated carbon for removing volatile organic carbon [1] have been reported as possible uses. Several studies have considered using bark as a resource for producing sec- ondary products. Furuya et al. (2006) [6] attempted to produce charcoal from bark. Furthermore, the extraction of essential oil from bark for aromatherapy was reported by Hanitriniaina et al. (2010) [7]. Spruce bark was considered as a potential source of sugar to produce ethanol [8]. Today, bark is primarily used as an inexpensive fiber material in the plastics industry [9]. Both applied and basic studies of bark have been conducted. Such research includes studies on the antifungal properties of bark, the inhibition to plant growth by bark, and terpenes production by bark to protect plants against herbivorous damage, as reported by Yang et al. (2004) [10], Naasz et al. (2009), and Courtois et al. (2012) [11], respectively. Bark is usually poor in nutrients such as nitrogen, phosphorous, and potassium; hence, the potential nutrient effects of bark have not been previously considered. Bark is generally perceived as a soil conditioning material or fertilizer, primarily because it is usually considered for its physical properties rather than its chemical properties. However, several studies researching the utility of bark as compost have been conducted in recent years [2,12-23]. Many properties of bark material have yet to be elucidated. Hence, all potential applications for bark should be identified, as universal standard criteria for its quality have yet to be established. Therefore, many case studies are currently being performed to better understand the potential uses of bark. In this study, the optimum mixing pattern was searched for komatsuna and tomato growth. In a recent study, investigating the impact of bark on komatsuna growth, Ishiguro et al. (2011) reported how different levels of bark maturity influence komatsuna growth. Based on these results, people who use bark as a form of soil conditioner/compost were provided with better insights on how to use bark as a cost 
saving material to improve vegetable production.

\section{MATERIAL AND METHODS}

\subsection{Soil for Experiment}

The surface soil of a university campus garden, which had been abandoned for several years in Toyama Prefectural University, was sampled and sieved with a $5 \mathrm{~mm}$ mesh. The total nitrogen content of the soil was $0.3 \%$.

\subsection{Bark}

Manyo bark (Hokuriku Port Service Co., Ltd.) was used for this experiment. The bark was treated under anaerobic static pile conditions for a long period (i.e., more than 20 years), without the use of any nutritional chemicals to accelerate digestion. Both coniferous and broad-leaved tree bark was used. Table 1 presents the guaranteed quality of Manyo Bark Fertilizer.

\subsection{Substrate for Aerobic Operation}

Dog food (Aijomonogatari beef taste: Easter) was used as substrate to promote aeration digestion. The dog food was composed of: amid acids $\geq 20.0 \%$, fat $\geq 5.0 \%$, fiber $\leq 6.0 \%$, ash $\leq 10.0 \%$, water content $\leq 10.0 \%$, calcium $\geq$ $1.0 \%$, phosphorous $\geq 0.8 \%$, salt $\geq 0.5 \%$, linoleic acid $\geq$ $1.0 \%$, vitamin $\mathrm{A} \geq 5000 \mathrm{IU} / \mathrm{kg}$, vitamin $\mathrm{B} 1 \geq 1.0 \mathrm{mg} / \mathrm{kg}$, vitamin $\mathrm{B} 2 \geq 2.2 \mathrm{mg} / \mathrm{kg}$, biotin $\geq 0.1 \mathrm{mg} / \mathrm{kg}$, and calories $\geq 290 \mathrm{kcal} / 100 \mathrm{~g}$. Trace constituents of the dog food included: potassium, magnesium, iron, copper, magnesium, zinc, iodine, selenium, vitamin (C, E, B6, and B12), pantothenic acid, niacin, folic acid, and choline.

\subsection{Bark Samples Used for the Experiment}

Original bark (Manyo Bark) was mixed with the dog-food at a 2:1 weight ratio. NABS (Not aerated bark samples) and ABS (Aerated bark samples) were used for this experiment. NABS were prepared by just mixing original bark with dog-food at a 2:1 ratio, and leaving it without aeration for 2 months. ABS was prepared by mixing original bark with dog-food at a 2:1 ratio, and then aerating it in a compost reactor for about 2 months.

\subsection{Chemical Fertilizer}

Ammonium sulfate (Kanto Chemical), superphosphate of lime (Kanto Chemical), and potassium chloride (Kanto Chemical) were used as nitrogen, phosphorous, and potassium supplies, respectively.

\subsection{Pots Used for the Experiment}

Wagner pots of 1/5000 (Fujiwara) were used for the experiments.

\subsection{Vegetables Used for the Experiment}

Hayadori cultivars of Komatsuna, also termed Japanese mustard spinach (Brassica rapa var. perviridis), and Momotaro-Haruka cultivars of tomato (Solanum lycopersicum) were used for the vegetable growing experiments.

\subsection{Methods Used for the Growing Tests}

For data analysis, standard deviations (SD) were basically applied except for the number of leaves which were not obtained enough for SD analysis.

1) Komatsuna Growing Test

Two tests were conducted, one basic and one applied. Nine and 13 types of test pots were prepared for the basic and applied growing tests, respectively (Table 2). A quantity of $0.6 \mathrm{~g}$ ammonium sulfate, $0.7 \mathrm{~g}$ superphosphate of lime, and $0.2 \mathrm{~g}$ potassium chloride was prepared for the $0.125 \mathrm{~g}$ chemical fertilizer (CF) pot preparation. For the $0.25 \mathrm{CF}$ pot preparation, $1.2 \mathrm{~g}, 1.4 \mathrm{~g}$, and $0.4 \mathrm{~g}$ of these components were used, respectively. For the $0.5 \mathrm{~g}$

Table 1. Quality of Manyo bark fertilizer.

\begin{tabular}{|c|c|c|c|c|}
\hline Item & Unit & Standard Value ${ }^{*}$ & Manyo Bark Fertilizer & Method \\
\hline Total Nitrogen & $\%$ (dry base) & $\geq 1.2$ & 1.5 & Sulfuric Acid Dissolving Method \\
\hline $\mathbf{K}_{2} \mathbf{O}$ & $\%$ (dry base) & $\geq 0.3$ & 0.4 & Atomic Absorption Spectrometry \\
\hline Organic Content & $\%$ (dry base) & $\geq 70$ & 84 & Ignition Loss \\
\hline Cation Exchange Capacity (CEC) & Meq/100 g (dry base) & $\geq 70$ & 78 & Shaking Method \\
\hline $\mathrm{C} / \mathrm{N}$ ratio & $\%$ & $\leq 35$ & 31 & Tyurin's Method \\
\hline $\mathbf{p H}$ & & $5.5-7.5$ & 7 & Glass Electrode \\
\hline Water Content & $\%$ & $55-65$ & 66 & Loss on Drying Test \\
\hline
\end{tabular}

*NPO Japan bark compost association. 
Table 2. Types of test pots prepared for komatsuna basic and applied growing tests.

\begin{tabular}{|c|c|c|c|}
\hline No. & Type & Description & Nitrogen Addition (g/pot) \\
\hline \multicolumn{4}{|c|}{ Basic Tests } \\
\hline 1 & Control & Soil only & - \\
\hline 2 & CF 0.25 & Chemical Fertilizer: $0.25 \mathrm{~g} /$ pot for each $\mathrm{N}, \mathrm{P}_{2} \mathrm{O}_{5}$, and $\mathrm{K}_{2} \mathrm{O}$ & 0.25 \\
\hline 3 & CF 0.5 & Chemical Fertilizer: $0.5 \mathrm{~g} /$ pot for each $\mathrm{N}, \mathrm{P}_{2} \mathrm{O}_{5}$, and $\mathrm{K}_{2} \mathrm{O}$ & 0.5 \\
\hline 4 & B100 & Bark $100 \%$ & 9.2 \\
\hline 5 & B50 & Bark $50 \%+$ Soil $50 \%$ & 4.6 \\
\hline 6 & B25 & Bark $25 \%+$ Soil $75 \%$ & 2.3 \\
\hline 7 & B100CF 0.25 & Bark $100 \%+$ Chemical Fertilizer: $0.25 \mathrm{~g} /$ pot for each $\mathrm{N}, \mathrm{P}_{2} \mathrm{O}_{5}$, and $\mathrm{K}_{2} \mathrm{O}$ & 9.45 \\
\hline 8 & B50CF 0.25 & Bark $50 \%+$ Chemical Fertilizer: $0.25 \mathrm{~g} /$ pot for each $\mathrm{N}, \mathrm{P}_{2} \mathrm{O}_{5}$, and $\mathrm{K}_{2} \mathrm{O}$ & 4.86 \\
\hline 9 & B25CF 0.25 & Bark $25 \%+$ Chemical Fertilizer: $0.25 \mathrm{~g} /$ pot for each $\mathrm{N}, \mathrm{P}_{2} \mathrm{O}_{5}$, and $\mathrm{K}_{2} \mathrm{O}$ & 2.55 \\
\hline \multicolumn{4}{|c|}{ Applied Tests } \\
\hline 1 & Control & Soil only & - \\
\hline 2 & CF 0.125 & Chemical Fertilizer: $0.125 \mathrm{~g} /$ pot for each $\mathrm{N}_{1} \mathrm{P}_{2} \mathrm{O}_{5}$, and $\mathrm{K}_{2} \mathrm{O}$ & 0.125 \\
\hline 3 & CF 0.25 & Chemical Fertilizer: $0.25 \mathrm{~g} /$ pot for each $\mathrm{N}, \mathrm{P}_{2} \mathrm{O}_{5}$, and $\mathrm{K}_{2} \mathrm{O}$ & 0.25 \\
\hline 4 & CF 0.5 & Chemical Fertilizer: $0.5 \mathrm{~g} /$ pot for each $\mathrm{N}, \mathrm{P}_{2} \mathrm{O}_{5}$, and $\mathrm{K}_{2} \mathrm{O}$ & 0.5 \\
\hline 5 & B50 & Bark $50 \%+$ Soil $50 \%$ & 4.6 \\
\hline 6 & NABS50 & NABS $50 \%+$ Soil $50 \%$ & 11.0 \\
\hline 7 & ABS50 & ABS $50 \%+$ Soil $50 \%$ & 8.1 \\
\hline 8 & NABS-N & NABS $330 \mathrm{~g}$ (wet base)/pot & 4.6 \\
\hline 9 & ABS-N & ABS $260 \mathrm{~g}$ (wet base)/pot & 4.6 \\
\hline 10 & NABS-N/2 & NABS $165 \mathrm{~g}$ (wet base)/pot & 2.3 \\
\hline 11 & ABS-N/2 & ABS $130 \mathrm{~g}$ (wet base)/pot & 2.3 \\
\hline 12 & NABS-N/4 & NABS $83 \mathrm{~g}$ (wet base)/pot & 1.2 \\
\hline 13 & ABS-N/4 & ABS $65 \mathrm{~g}$ (wet base)/pot & 1.2 \\
\hline
\end{tabular}

CF pot preparation, $2.4 \mathrm{~g}, 2.8 \mathrm{~g}$, and $0.8 \mathrm{~g}$ of ammonium sulfate, superphosphate of lime, and potassium chloride were used, respectively. Three liters of bark and soil was placed in each pot. The basic and applied tests were conducted from May 9 to June 11 and July 2 to August 2 in 2007, respectively. The growing tests were performed in a greenhouse. All experiments were conducted in triplicate. After seeding, the young plants were culled, with 3 komatsuna plants being selected for surveying from each pot.

The growth and yield survey of komatsuna was conducted o these plants. The growth survey was initiated 2 weeks after seeding, and the height of the plant was measured, and the number of leaves (excluding young leaves) was counted. For the yield survey, the weight of the above ground plant part was measured immediately after harvest, and the dry weight of the plant was also measured after drying. The average for each parameter was used in the graphs.

2) Tomato Growing Test

Nine types of test pots were prepared for the growing tests (Table 3). Only applied test was done in this test. In this survey, a mix ratio of 1:1 for bark and soil (B50 pot) and a mix ratio of 1:3 for bark and soil (B25 pot) were prepared. For the $\mathrm{CF}$ pots, $0.25 \mathrm{~g}$ and $0.5 \mathrm{~g}$ of each of $\mathrm{T}-\mathrm{N}, \mathrm{P}_{2} \mathrm{O}_{5}$, and $\mathrm{K}_{2} \mathrm{O}$ were prepared. A quantity of $1.2 \mathrm{~g}$ ammonium sulfate, $1.4 \mathrm{~g}$ superphosphate of lime, and 0.4 $\mathrm{g}$ potassium chloride were used for the $0.25 \mathrm{~g} \mathrm{CF}$ pot preparation.

A quantity of $2.4 \mathrm{~g}, 2.8 \mathrm{~g}$, and $0.8 \mathrm{~g}$ of these components, respectively, were used for the for $0.5 \mathrm{~g} \mathrm{CF}$ pot preparation. Three liters of bark and soil were placed in a 
Table 3. Nine types of test pots prepared for tomato growing tests.

\begin{tabular}{|c|c|c|c|}
\hline No. & Type & Description & Nitrogen Addition (g/pot) \\
\hline 1 & Control & Soil only & - \\
\hline 2 & CF 0.25 & Chemical Fertilizer: $0.25 \mathrm{~g} /$ pot for each $\mathrm{N}, \mathrm{P}_{2} \mathrm{O}_{5}$, and $\mathrm{K}_{2} \mathrm{O}$ & 0.25 \\
\hline 3 & CF 0.5 & Chemical Fertilizer: $0.5 \mathrm{~g} /$ pot for each $\mathrm{N}, \mathrm{P}_{2} \mathrm{O}_{5}$, and $\mathrm{K}_{2} \mathrm{O}$ & 0.5 \\
\hline 4 & B25 & Bark 25\% + Soil $75 \%$ & 2.55 \\
\hline 5 & B50 & Bark 50\% + Soil 50\% & 5.10 \\
\hline 6 & NABS25 & NABS $25 \%+$ Soil $75 \%$ & 5.04 \\
\hline 7 & ABS25 & ABS $25 \%+$ Soil $75 \%$ & 6.75 \\
\hline 8 & NABS50 & NABS $50 \%+$ Soil $50 \%$ & 10.08 \\
\hline 9 & ABS50 & ABS $50 \%+$ Soil $50 \%$ & 13.50 \\
\hline
\end{tabular}

pot. The tests were conducted from November 13, 2007 to January 16,2008 . The growing tests were performed in a greenhouse. All experiments were repeated 5 times. Young tomato plants of $30 \mathrm{~cm}$ in height were used, with 1 plant being placed in each pot. The effectiveness of ABS (aerated bark sample) was evaluated by the amount that tomato plants grew. The growing test survey was initiated immediately after the young plants were planted. The fruit clusters and plant heights were measured once a week. The averages of the test parameters were used in the graphs.

\section{RESULTS AND DISCUSSION}

\subsection{Quality Analysis of NABS and ABS}

A quality analysis comparing both NABS and ABS was completed in this study (Table 4). The percentage of $\mathrm{P}_{2} \mathrm{O}_{5}$ and $\mathrm{K}_{2} \mathrm{O}$ and $\mathrm{CEC}$ values was higher in ABS compared to NABS.

These values were probably higher in aerated bark, due to it being subject to greater levels of degradation. The percentage of $\mathrm{P}_{2} \mathrm{O}_{5}$ and $\mathrm{K}_{2} \mathrm{O}$ and $\mathrm{CEC}$ values was higher in NABS and ABS compared to original bark samples. This difference was probably caused by the addition of dog-food. In comparison, the $\mathrm{C} / \mathrm{N}$ ratio was lower in NABS and ABS compared to original bark samples. This difference was because of higher nitrogen content and lower bark content in NABS and ABS. Bark usually contains high quantities of persistently degradable organic materials, and fewer easily degradable organic materials [15]. Because of aeration, the activity of aerobic bacteria may have been enhanced, causing easily degradable organic materials and persistently degradable organic materials to be degraded in some parts of the pile. Consequently, the organic content of NABS and ABS decreased. Therefore, the addition of easily degradable organic materials (i.e., dog-food) accelerated the organic
Table 4. Quality of NABS and ABS.

\begin{tabular}{cccccc}
\hline Item & Unit & $\begin{array}{c}\text { Standard } \\
\text { Value }^{*}\end{array}$ & $\begin{array}{c}\text { Manyo Bark } \\
\text { Fertilizer }\end{array}$ & NABS ABS \\
\hline Total Nitrogen & $\%$ (dry base) & $\geq 1.2$ & 1.5 & 3.0 & 2.9 \\
$\mathbf{P}_{2} \mathbf{O}_{5}$ & $\%$ (dry base) & $\geq 0.5$ & 1.4 & 8.8 & 12 \\
$\mathbf{K}_{2} \mathbf{O}$ & $\%$ (dry base) & $\geq 0.3$ & 0.4 & 0.9 & 1.4 \\
Organic Content & $\%$ (dry base) & $\geq 70$ & 84 & 42 & 39 \\
$\begin{array}{cccccc}\text { Cation Exchange } \\
\text { Capacity (CEC) }\end{array}$ & $\begin{array}{c}\text { Meq/100 g } \\
\text { (dry base) }\end{array}$ & $\geq 70$ & 78 & 86 & 92 \\
C/N Ratio & $\%$ & $\leq 35$ & 31 & 14 & 14 \\
pH & & $5.5-7.5$ & 7 & 7 & 7 \\
Water Content & $\%$ & $55-65$ & 66 & 54 & 40 \\
\hline
\end{tabular}

${ }^{*}$ : NPO Japan bark compost association.

degradation of bark, causing an increase in CEC values. As a result, the $\mathrm{C} / \mathrm{N}$ ratio of NABS and ABS became less than half that of the original bark. In addition, the water content of NABS and ABS was lower than that of the original bark. This phenomenon implied that water vapor is produced during the organic degradation of bark. ABS was subject to aerobic organic degradation throughout the 2 month period, while NABS may have also been subject to aerobic conditions at and near the surface during the 2 month preparation period.

\subsection{Results of the Komatsuna Growing Tests}

1) Basic Tests

The results of the basic tests are shown Figures 1-3 and Photo 1. Based on the results, B50 showed the greatest growth among the bark test pots (i.e., B100, B50, and $\mathrm{B} 25$ ).

B100 showed the least growth among all test pots, with this result supporting that discussed by Ishiguro et 


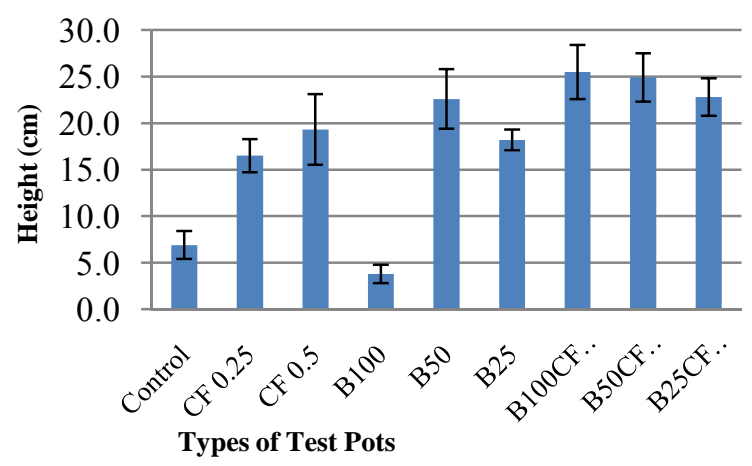

Figure 1. Height of komatsuna in the basic growing test.

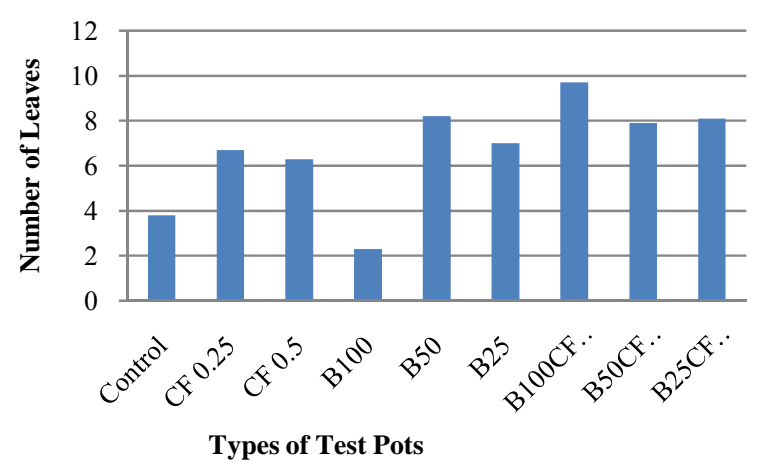

Figure 2. Number of komatsuna leaves in the basic growing test.

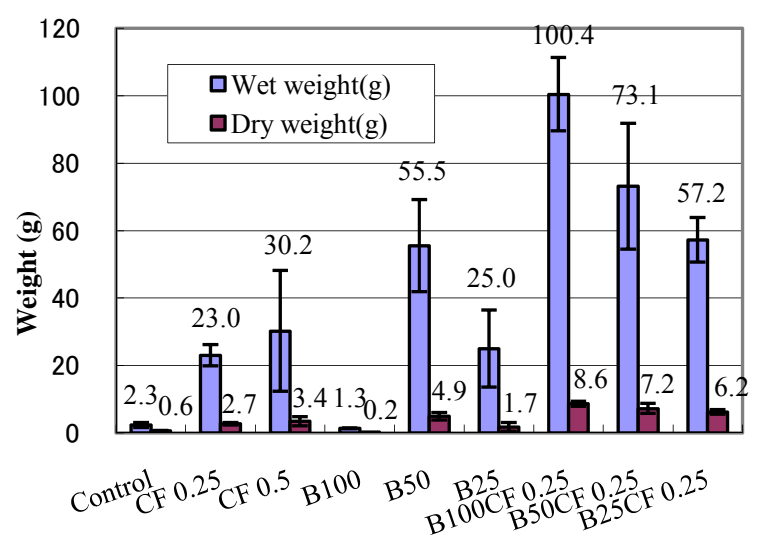

Type of Test Pots

Figure 3. Weight of komatsuna plants in the basic growing test.

al. (2011). The excessive use of bark causes negative damage to plant growth, because water permeability is increased too much. The B100 results were worse than the control; however, 25 or $50 \%$ bark mixes improved the growth results. For the $\mathrm{CF}$ test pots, $\mathrm{CF} 0.5$ produced better results than CF 0.25 ; hence, increasing the amount of chemical fertilizer produced better growth results. Comparison of $\mathrm{CF}$ and $\mathrm{B}$ pots showed that B50 had the highest growth for all parameters (i.e., height, number of leaves, and weight).

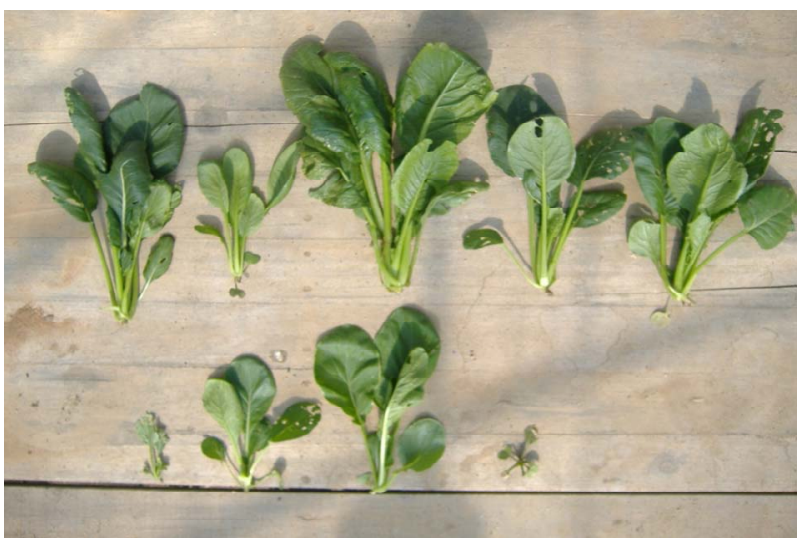

Photo 1. Komatsuna plants in the basic growing tests. Upper line: B50, B25, B100CF 0.25, B50CF 0.25, B25CF 0.25; Lower line: Control, CF 0.25, CF 0.5, B100.

In the pots combining $\mathrm{CF}$ and bark (i.e., $\mathrm{B} 100-\mathrm{CF} 0.25$, B50-CF 0.25, and B25-CF 0.25), the pots with the highest amount of bark exhibited the greatest growth. In the B tests, B50 exhibited the highest growth; however, B100 (100\% bark) exhibited the highest growth when mixed with chemical fertilizer (B100-CF 0.25).

This phenomenon might be due to the high capacity of bark to retain nutrients. Hence, bark mixed with chemical fertilizer produced the greatest improvement in komatsuna growth. We used the results of this study to generate several recommendations for using bark as a soil conditioner/compost. The use of bark alone is not recommended. The use of soil alone is better than the use of bark alone. Bark should be used in combination with soil. Bark mixed with soil produced a better result than soil mixed with chemical fertilizer. The used of bark alone produced a better result than chemical fertilizer alone, with no significant difference to bark mixed with soil samples. Therefore, a chemical fertilizer should also be applied when using bark alone or bark with soil to obtain the optimum growth for komatsuna. Previous reports have primarily focused on the physical properties of bark, rather than its chemical properties $[13,15,20,21]$. In conclusion, the basic test conducted in this study supports these previous studies, demonstrating that the positive role of bark as a compost may be primarily due to its physical attributes, rather than its chemical properties.

\section{2) Applied Tests}

The results of the applied tests are shown in Figures 4-6 and Photo 2. Since B50 produced the best result of the B pots in the basic tests, B50 was used as the standard for the bark mix ratio in the applied tests. Among the 50\% mixed tests (B50, NABS50, and ABS50), there was no significant difference between B50 and ABS50; however, growth was weaker for NABS50 compared to the other two types. B50 and ABS50 produced similar results to $\mathrm{CF}$ pots. Although the nitrogen content in $\mathrm{NABS}$ and $\mathrm{ABS}$ was higher compared to B50, growth 


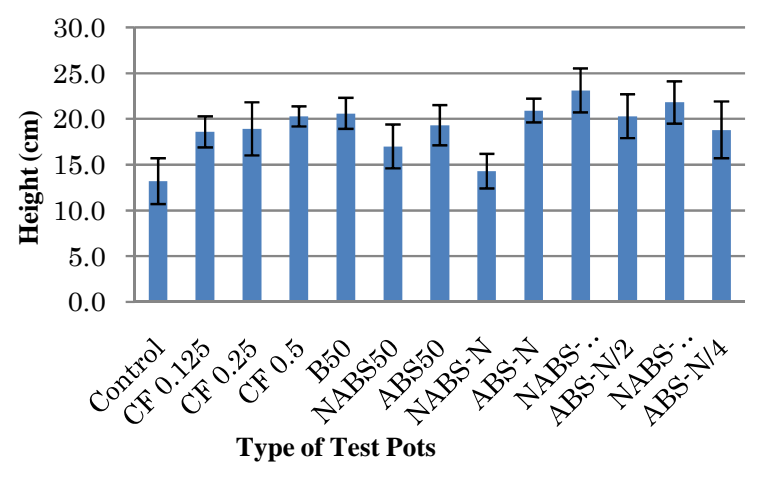

Figure 4. Height of komatsuna plants in the applied growing tests.

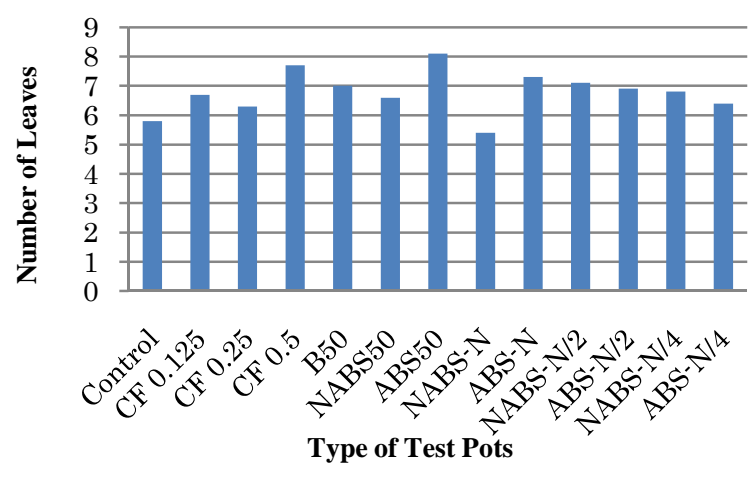

Figure 5. Number of komatsuna leaves in the applied growing tests.

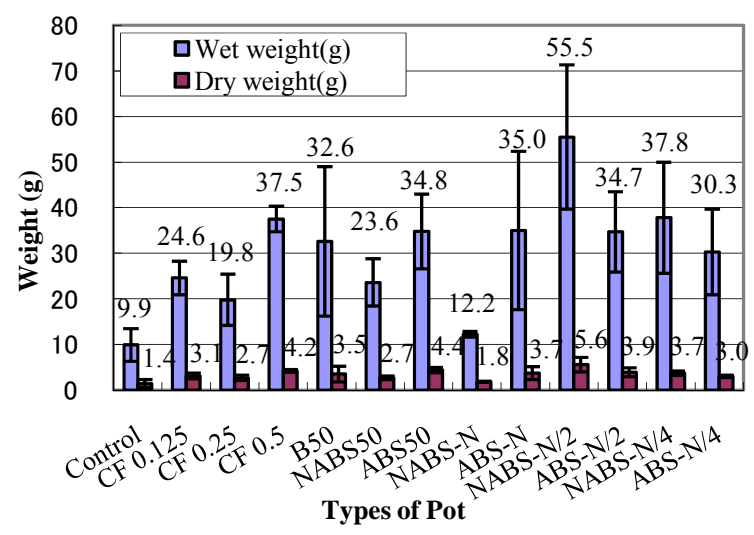

Figure 6. Weight of komatsuna plants in the applied growing tests.

using ABS50 was almost the same as in B50, whereas growth in NABS50 was worse than in B50. This result indicates that aerating bark does not enhance the properties of bark. A small amount of organic acid might be produced in the bark pile of NASB50 [20]; hence, komatsuna growth might be affected by the acid, which negatively impacted plant growth in this pot type.

komatsuna grew better in ABS50 than in NABS50. One explanation might be that NABS had higher bark content than ABS, supporting the results of the basic test. Aeration might have caused dog-food to rapidly de-

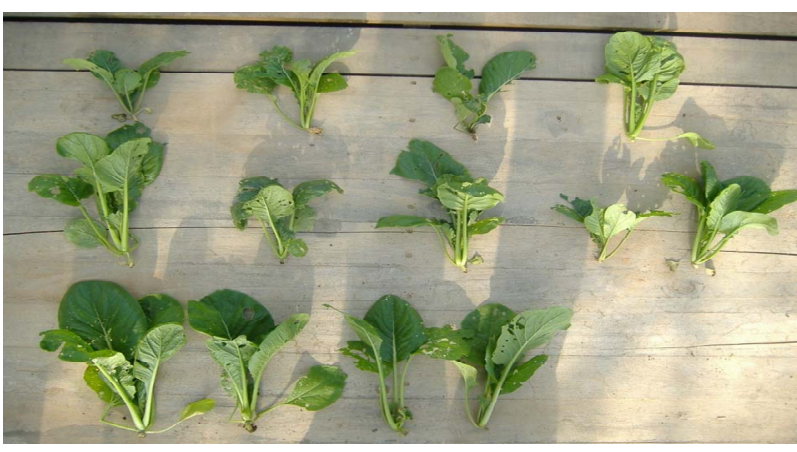

Photo 2. Komatsuna plants in the applied growing tests. Upper line (Left to Right): Control, CF 0.125, CF 0.25, CF 0.5; Middle line (Left to Right): B50, NABS50, ABS50, NABS-N, ABS-N; Lower Line: NABS-N/2, ABS-N/2, NABS-N/4, ABS-N/4.

compose to a mineral level, with ABS50 reaching the same stable quality level of the original bark. The types of $-\mathrm{N},-\mathrm{N} / 2$, and $-\mathrm{N} / 4$ described the amount of bark in pots, with bark and soil being mixed to fill pots. By reducing the amount of bark in pots, the nitrogen content of the pots also decreased. The result of NABS-N was poor compared to ABS50, which was possibly because of the organic acid generated under anaerobic conditions remained in NABS. In other words, the bark was immature. Previous studies have also reported the negative effects of immature bark [15]. The NABS-N sample was very similar to the pure NABS sample; hence, this quantity of organic acid might be sufficiently high to negatively affect komatsuna growth. In comparison, in the $-\mathrm{N} / 2$ and $-\mathrm{N} / 4$ test pots, NABS samples had a positive effect on komatsuna growth. These differences were simply caused by different amounts of bark material being used in the pots. Supporting the results of the basic test, a higher mix ratio of bark enhanced komatsuna growth. As shown in Table 2, NABS-N/2 and -N/4 contained higher amounts of bark material than ABS-N/2 and $-\mathrm{N} / 4$ tests. In conclusion, this test supported the original hypothesis that the aeration of bark does not always improve plant growth.

\subsection{Results of the Tomato Growing Tests}

The results of the tomato growing tests are shown in Figures 7-9 and Photo 3. Unlike komatsuna, tomato growth remained similar or better in B25 and B50. In the komatsuna test, growth in B25 was significantly lower compared to B50.

Compared to $\mathrm{CF}$, the $\mathrm{B}$ tests produced consistently better growth results compared to the CF tests. The combination of soil and chemical fertilizer is not recommended for tomato growth, whereas a combination of bark and soil enhances growth. The aeration of bark did not appear to generate any benefit on tomato growth. NASB25, ABS25, and ABS50 produced similar results; however, NASB50 inhibited growth, as in komatsuna. 


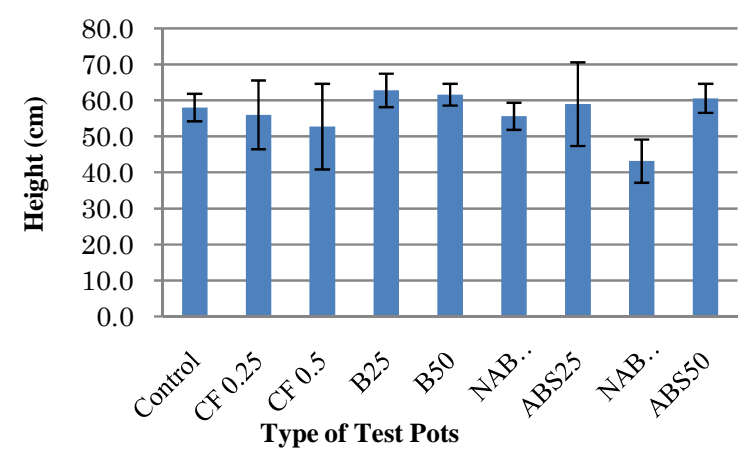

Figure 7. Height of tomatoes in the growing tests.

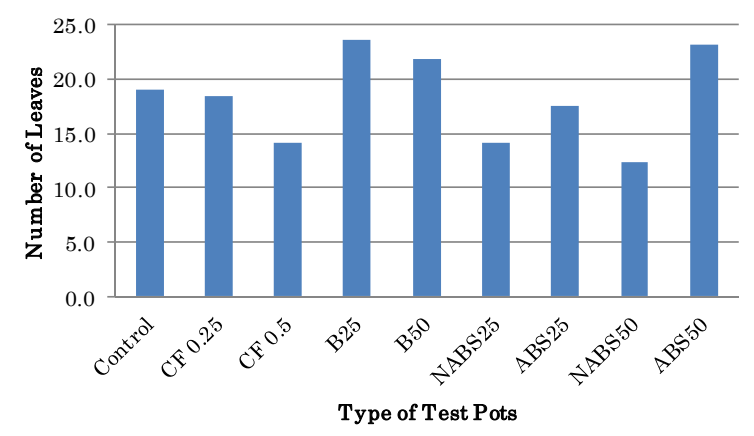

Figure 8. Number of tomato leaves in the growing tests.

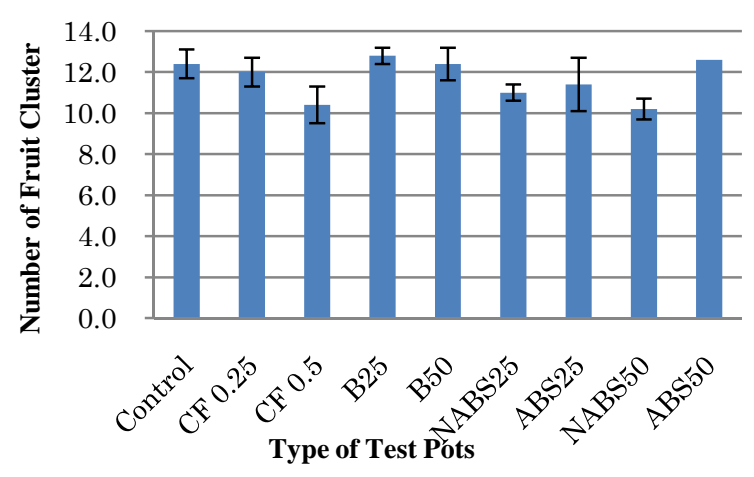

Figure 9. Number of tomato plant fruit clusters in the growing tests.

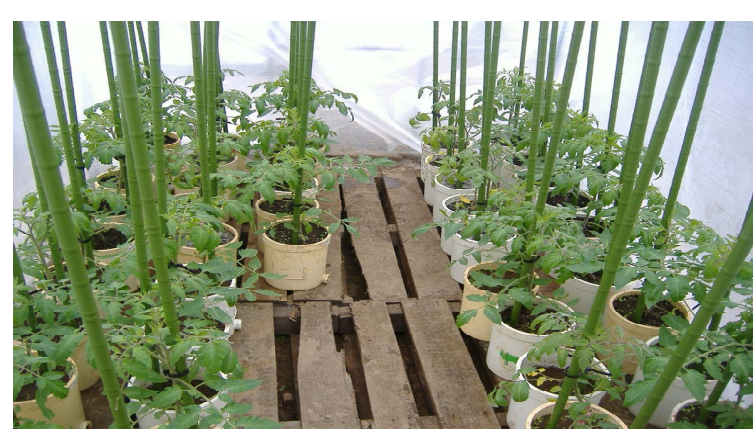

Photo 3. Tomato plants in the applied growing tests.

This result may have been obtained because the NASB sample might have contained a small amount of organic acid; consequently, tomato growth was poorer in this pot.
In conclusion, bark application to soil had a positive result on tomato growth.

\section{CONCLUSION}

Several conclusions were obtained from the komatsuna growing tests. A quantity of $25 \%$ and $50 \%$ bark mixed with soil enhanced komatsuna growth, presenting similar or better growth results compared to 0.25 and 0.5 g chemical fertilizer, respectively. komatsuna could not grow in $100 \%$ bark, with high quantities of bark negatively impacting komatsuna growth. komatsuna grew better under a combination of bark and chemical fertilizer, compared to bark alone. Larger vegetables do not necessarily sell better, as supermarkets have standard sizes, and do not sell oversized vegetables. For komatsuna, $22-26$ and $26-30 \mathrm{~cm}$ plant heights fall within the acceptable size ranges for medium and large, respectively. komatsuna in excess of $30 \mathrm{~cm}$ height cannot be sold in supermarkets. However, the vegetables that fall in this size range are sold in mixed vegetable packages, as they are chopped and mixed with other vegetables. Therefore, the results obtained in this study may contribute in the regulation of komatsuna height, producing plants that fall within the strict height range standards for sale. Unlike komatsuna, tomato was minimally impacted by fertilizer and bark physical properties, with aerated bark being more effective at enhancing tomato growth compared to komatsuna. In conclusion, the current study confirmed that bark was a highly effective material at enhancing vegetable growth, but that its effectiveness might vary for different types of vegetables. We might have to find it for each vegetable.

\section{REFERENCES}

[1] Inoue, J., Kawarada, K., Sugimori, H., Hagiwara, T., Watanabe, A. and Shiraishi, M. (2011) Development of activated carbon blended with waste bark. Journal of the Japan Institute of Energy, 90, 66-74. doi:10.3775/jie.90.66

[2] Ishiguro, Y., Kitamura, R., Sawagashira, Y. and Fukui, H. (2010) The influence of $\mathrm{C} / \mathrm{N}$ ratio and nitrogen content of material for bark compost on composting process. Japanese Journal of Farm Work Research, 45, 175-181. doi:10.4035/jsfwr.45.175

[3] Koyama, F., Shimizu, K., Matsubara, E., Yoshida, E. and Kondo, R. (2011) Reduction of ammonia emission during composting of poultry manure by covering with cedar bark. Mokuzai Gakkaishi, 57, 370-376. doi:10.2488/jwrs.57.370

[4] Naasz, R., Caron, J., Legault, J.and Pichette, A. (2009) Efficiency factors for bark substrates: Biostability, aeration, or phytotoxicity. Soil and Water Management and Conservation, 73, 780-791.

[5] Van, T.K., Kang, Y. and Sakurai, K. (2005) Boron fixation and its release in soils and bark compost. Soil Science and 
Plant Nutrition, 51, 69-74. doi:10.1111/j.1747-0765.2005.tb00008.x

[6] Furuya, N., Watanabe, K. and Sakawa, M. (2006) Carbonization process of bark. The Japan Institute of Energy, 43, 111-112.

[7] Hanitriniaina, S.A., Chantal, M., Panja, R., Falihery, R., Philippe, Collas de Chatelperron, and Pascal, D. (2010) Chemical composition of essential oils from bark and leaves of industrial trees of Ravensara aromatica Sonnerat. Journal of Essential Oil Research, 22, 66-70. doi:10.1080/10412905.2010.9700267

[8] Kemppainen, K., Inkinen, J., Uusitalo, J., Nakari-Setala, T. and Siika-Aho, M. (2012) Hot water extraction and steam explosion as pretreatments for ethanol production from spruce bark. Bioresource Technology, 117, 131-139. doi:10.1016/j.biortech.2012.04.080

[9] Yemele, M.C.N., Koubaa, A., Cloutier, A., Soulounganga, P., Stevanovic, T. and Wolcott, M.P. (2013) Effects of hot water treatment of raw bark, coupling agent, and lubricants on properties of bark/HDPE composites. Industrial Crops and Products, 42, 50-56. doi:10.1016/i.indcrop.2012.05.012

[10] Yang, D.-Q., Wang, X.-M., Shen, J. and Wan, H. (2004) A rapid method for evaluating properties of various barks. Forest Products Journal, 54, 37-39.

[11] Courtois, E.A., Baraloto, C., Paine, C.E.T., Petronelli, P., Blandinieres, P.-A., Stien, D., Höuel, E., Bessière, J.-M. and Chave, J. (2012) Differences in volatile terpene composition between the bark and leaves of tropical tree species. Phytochemistry, 82, 81-88. doi:10.1016/j.phytochem.2012.07.003

[12] Ishiguro, Y., Kumagai, J.-I. and Fukui, H. (2009) Relationship between the composting period of bark compost and microbial activity on the immobilization of ammonia. Journal of the Japan Society of Material Cycles and Waste Management, 20, 61-67. doi:10.3985/jjsmcwm.20.61

[13] Ishiguro, Y., Sawagashira, Y., Kitamura, R.N. and Fukui, H. (2011) Effects of continuous applications of bark compost with different levels of maturity on physicochemical properties of soil in Komatsuna (Brassica rapa L. Perviridis) culture house. Horticultural Research, 10, 341-348. doi:10.2503/hrj.10.341

[14] Kaneda, Y. (2006) Pursuing highly functional bark fertilizer promising stable production and safety and comfort.
Japan Soil Association Hojo to Dojo, 38, 12-18.

[15] Konno, K., Hirai, Y. and Higashida, S. (1986) The availability of nitrogen from bark composts and effects of their application on growth and yields of upland crops. Bulletin of Hokkaido Research Organization Agricultural Experiment Stations, 55, 33-43.

[16] Maeda, T., Ono, M. and Kawai, S. (2005) Effects of material temperature on decompostion and nitrogen conversion during compost maturing-Study on the compost made of dairy cow manure and shredding bark. Journal of the Society of Agricultural Structures, 36, 47-53.

[17] Nakamura, K. (2010) Using urea to decompose polylactic acid in bark compost. Research Report of Institute of Technology, Shimizu Corporation, 87, 111-117.

[18] Nakatsu, S. and Tamura, H. (2008) Effects of thirty years continuous application of organic materials (bark manure and crop residues) on total carbon, total nitrogen and physical characteristics of upland field soil in light colored andosol in Hokkaido. Japanese Journal of Soil Science and Plant Nutrition, 79, 139-145.

[19] Sarles, R.L. (1973) Using and marketing bark residues. Forest Product Journal, 23, 10-14.

[20] Tajika, K., Takano, R. and Mizukuchi, Y. (1993) Utilization of bark for soil conditioner II. Production of hardwood bark composts sufficiently suitable for agricultural use. Journal of the Toyama Forestry and Forest Products Research Center, 7, 49-56.

[21] Tokuhashi, S. and Kubota, M. (1976) Soil amendment abilities of the bark compost compared with the rice straw in vinylhouse culture. Bulletin of the Kochi Inst Agricultural \& Forest Science, 8, 39-47.

[22] Wakasawa, H., Kawai, T., Kamiya, M., Hotta, K., Aoshima, Y., Suzuki, N., Nakagami, S., Yamada, K., Hori, K., Horiuchi, M., Takahashi, K., Mizumoto, M. and Matsumoto, M. (1994) Effects of continuous application of organic matters on yellow soil and andosoil in upland field I. Changes of chemical and physical properties of soil and yield of cabbage and sweetpotato. Bulletin of the Shizuoka Agricultural Experiment Station, 38, 99-106.

[23] Zambrano, M., Freer, J., Baeza, J., Villarroel, M. and Vidal, G. (2007) Using a second-order polynominal model to determine the optimum dregs/bark ratio for industrial-Biosolid composting: The initial conditioning stage. Waste Management and Research, 25, 319-326. doi: $10.1177 / 0734242 \times 07075037$ 